\title{
A novel assay for the detection of bioactive volatiles evaluated by screening of lichen-associated bacteria
}

OPEN ACCESS

Edited by:

Paolina Garbeva

Netherlands Institute of Ecology (NIOO-KNAW), Netherlands

Reviewed by:

Laure Weisskopf

Agroscope, Switzerland

Marco Kai,

University of Rostock, Germany

${ }^{*}$ Correspondence:

Gabriele Berg,

Institute of Environmental Biotechnology, Graz University of Technology, Petersgasse 12, 8010

Graz, Austria

gabriele.berg@tugraz.at

Specialty section:

This article was submitted to Plant-Microbe Interaction, a section of the journal Frontiers in Microbiology

Received: 05 January 2015 Accepted: 17 April 2015 Published: 01 May 2015

Citation:

Cernava T, Aschenbrenner IA, Grube M, Liebminger S and Berg G (2015) A novel assay for the detection of bioactive volatiles evaluated by screening of lichen-associated bacteria. Front. Microbiol. 6:398. doi: 10.3389/fmicb.2015.00398

\section{Tomislav Cernava ${ }^{1}$, Ines A. Aschenbrenner ${ }^{1,2}$, Martin Grube ${ }^{2}$, Stefan Liebminger ${ }^{3}$ and Gabriele Berg ${ }^{1 *}$}

${ }^{1}$ Institute of Environmental Biotechnology, Graz University of Technology, Graz, Austria, ${ }^{2}$ Institute of Plant Sciences, University of Graz, Graz, Austria, ${ }^{3}$ Roombiotics GmbH, Graz, Austria

Volatile organic compounds (VOCs) produced by microorganisms are known both for their effect on pathogens and their role as mediators in various interactions and communications. Previous studies have demonstrated the importance of VOCs for ecosystem functioning as well as their biotechnological potential, but screening for bioactive volatiles remained difficult. We have developed an efficient testing assay that is based on two multi-well plates, separated by a sealing silicone membrane, two tightening clamps, and variable growth media, or indicators. The experiment design as presented here is a novel and robust technique to identify positive as well as negative VOC effects on the growth of a target organism and to test for specific substances e.g., hydrogen cyanide which can be detected with a suitable indicator. While the first pre-screening assay is primarily based on indicator color change and visible growth diameter reduction, we also introduce an advanced and quantitatively precise experiment design. This adaptation involves qPCR-based quantification of viable target cells after concluding the treatment with VOCs. Therefore, we chose preselected active isolates and compared the partial $16 \mathrm{~S}$ rRNA gene copy number of headspace-exposed $E$. coli with non-treated controls. Separately obtained headspace SPME and GC/MS-based profiles of selected bacterial isolates revealed the presence of specific and unique signatures which suggests divergent modes of action. The assay was evaluated by screening 100 isolates of lung lichen-associated bacteria. Approximately one quarter of the isolates showed VOC-based antibacterial and/or antifungal activity; mainly Pseudomonas and Stenotrophomonas species were identified as producers of bioactive volatiles.

Keywords: volatiles, VOCs, antifungal, antibacterial, lichen symbiosis

\section{Introduction}

Volatile organic compounds (VOCs) are organic compounds that have a high vapor pressure at ordinary room temperature. VOCs are produced by the majority of organisms and they often function as communication molecules (Effmert et al., 2012). The most notable characteristic of all VOCs is the extent of their range of influence as compared to non-volatile substances. While other secreted metabolites rely on close contact between interacting organisms or diffusion through 
separating matter, VOCs can overcome much greater distances. Bacterial as well as fungal strains produce a broad spectrum of bioactive VOCs with multi-functional effects, which are not restricted to the same species. Their action across organismal kingdoms was shown by Ryu et al. (2003) who demonstrated that bacterial volatiles promoted growth in Arabidopsis thaliana. In contrast, some bacterial isolates were also shown to reduce the growth of $A$. thaliana through emission of bioactive volatiles (Vespermann et al., 2007; Blom et al., 2011; Weise et al., 2013). Moreover, bacterial VOCs were shown to be able to suppress the growth of soil-borne pathogenic fungi, e.g., Rhizoctonia solani (Kai et al., 2007). Bacteria are able to communicate over long distances within the root system, both among bacteria and with plant hosts, where they elicit induced systemic resistance (ISR) and growth promotion (Farag et al., 2013). VOCs emitted by different soil bacteria can affect the growth, antibiotic production, and gene expression of soil bacteria (Garbeva et al., 2014). Owing to these multi-functional roles of VOCs, they have an enormous potential for biotechnological applications (Strobel, 2006; Schalchli et al., 2014). Currently, there is no efficient testing assay that allows for rapid screening of bioactive volatile metabolites in interrelation between two different microorganisms within the same headspace.

Host-associated microbiomes are important reservoirs for VOC-producing organisms because communication and pathogen defense are essential functions of the microbiome, and recently shown to be integral for healthy plant and human life (Blaser et al., 2013; Philippot et al., 2013). For the rhizosphere microbiome located on/in plant roots, the proportion of VOC producers is often high because in plants the root-associated microbiome acts as a primary protection shield against soil-borne pathogens (Cook, 1990; Weller et al., 2002). A similar role was also attributed to bacteria in the self-sustaining lichen symbiosis (Grube et al., 2015). In each microbiome a certain proportion of microorganisms with antagonistic activity against pathogens is involved in this function. Using a combination of metagenomic, -proteomic, and cultivation approaches, a proportion of $7 \%$ antagonists was identified for the lung lichen (Grube et al., 2015). Identification of antagonistic microorganisms is still a challenge (Berg et al., 2013), but nevertheless important for a more profound understanding of ecosystem functioning and also a necessary tool for bioprospecting in biotechnology (Strobel, 2006). The discovery of novel bioactive compounds facilitates improvement in disinfection strategies and drug discovery, both of which are in high demand due to the increasing rates of resistance to antibiotics (Woolhouse and Farrar, 2014). Antagonistic microorganisms harbor a vast potential to produce active biomolecules for direct activity against pathogens but also for mediators in various interactions, e.g., pathogen defense, quorum sensing, microorganism-host-interaction. Some of these biomolecules are highly active modifications of known antimicrobial substances and are therefore less susceptible to existing resistance mechanisms. In the past, most efforts focused on antibiotics for which high-throughput screening strategies were already developed (Conery et al., 2014; Seyedsayamdost, 2014). Although previous studies have demonstrated promising effects of bacterial and fungal volatile compounds, they are difficult to detect as well as to identify. Due to their inspiring odors, lichen extracts are used as raw materials in perfumery (Joulain and Tabacchi, 2009). As the specificity of bacterial communities in this phylogenetically old symbiosis was only recently detected (Grube et al., 2009), nothing is yet known about VOCs produced by the abundant lichen-associated bacteria.

The objective of our study was to develop a well platebased and cost-effective testing assay for the emission of bioactive VOCs. We chose lichen-associated bacteria for evaluation purposes. One hundred lichen-associated bacterial isolates were tested for volatile antagonistic activity in order to evaluate our assay. A noteworthy screening assay for biological hydrogen production developed by Schrader et al. (2008) was used as the basis for developing our testing system. The assay is based on two micro-well plates, separated by a sealing silicone membrane, two tightening clamps, and variable growth media or indicators. The suggested experiment design can be used to differentiate between target organism inhibition or growth promotion by a pure substance and also for the same effects caused by volatile mixtures emitted by living microorganisms. This, as well as an increased throughput compared to classic single plate-tests illustrates the novelty of the presented assay in comparison to already described experiment setups. In addition, it can be employed to test for specific substances which can be detected with a suitable indicator (Figure 1). Using this design we identified 30 out of 100 lichenassociated bacterial isolates, which produced bioactive volatiles and induced growth inhibition in two distinct target organisms. Since many lichenicolous organisms are characterized by slow growth rates and difficult or impossible to grow on media, two classic model targets were employed for evaluation purposes. $E$. coli was used in this experimental approach as a model for a typical human pathogen and $B$. cinerea as a model for a plant pathogen. Additional GC/MS-based headspace analysis with different lichen-associated isolates was applied to demonstrate the occurrence of isolate-specific VOC profiles.

\section{Material and Methods}

\section{Isolation of Lichen-Associated Bacteria}

Lobaria pulmonaria lichen thalli were sampled from three different locations in Austria (Tamischbachgraben, N $47^{\circ} 32^{\prime} 40^{\prime \prime}$, E $14^{\circ} 37^{\prime} 35^{\prime \prime}$, Johnsbach, N $47^{\circ} 38^{\prime} 07^{\prime \prime}$, E $14^{\circ} 44^{\prime} 45^{\prime \prime}$, and St. Oswald ob Eibiswald, N $46^{\circ} 44^{\prime} 50^{\prime \prime}$, E $\left.15^{\circ} 04^{\prime} 26^{\prime \prime}\right)$. The lichen samples were ground with mortar and pestle, and subsequently combined with a ratio of $1: 100.85 \%$ sterile $\mathrm{NaCl}$ in a lab stomacher to form a homogenate (BagMixer; Interscience, St Nom, France). The diluted fractions were then plated onto agars R2A (Carl Roth, Karlsruhe, Germany), R2A with $25 \mu \mathrm{g} \mathrm{ml}^{-1}$ cycloheximide, starch casein agar (SCA; Küster and Williams, 1964), and ISP2 (Shirling and Gottlieb, 1966). Distinctive bacterial colonies were transferred onto R2A plates for sub-cultivation within 5 days of incubation at room temperature. After subsequent testing for antagonism against different pathogens among other physiological tests, 100 lichen-associated bacterial isolates were selected out of 388 available isolates from the in-house culture collection. All of these isolates met at least one of the following criteria: (i) antagonistic activity against $E$. coli $\mathrm{K} 12$, (ii) antagonistic 


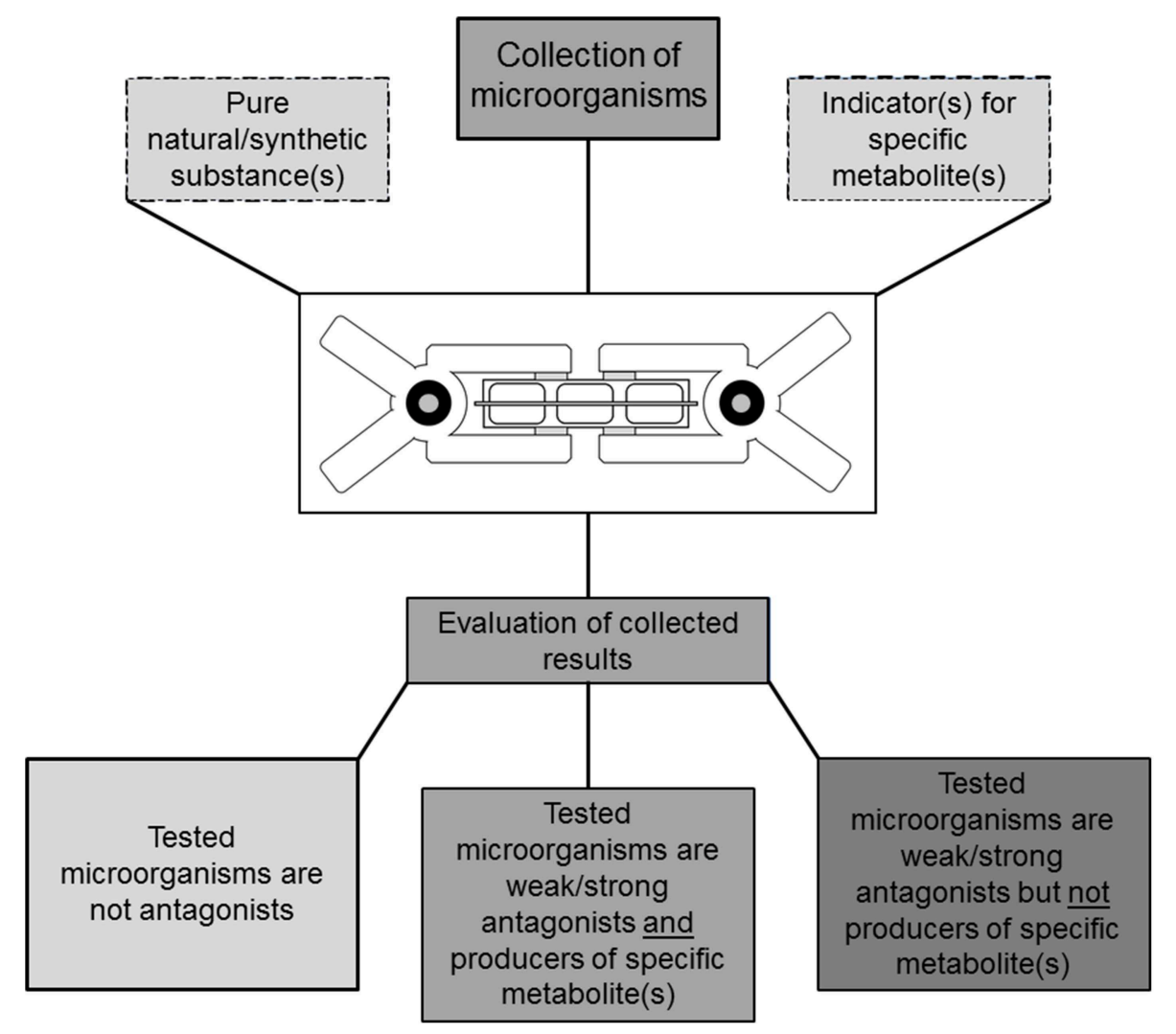

FIGURE 1 | Illustration of a TCVA-based screening approach for bioactive volatile compounds. The experiments are based on microorganism cultures suitable for cultivation in well-plates. Parallel setup of different experiments facilitates selectivity and can be used to eliminate producers of predefined compounds e.g., $\mathrm{HCN}$ if indicator substances are available. Utilization of additional reference substances enables gradual evaluation of visually inspected experiments. activity against Staphylococcus aureus ATCC 25923, (iii) antagonistic activity against Botrytis cinerea (SCAM, culture collection of the institute of Environmental Biotechnology, Austria), (iv) antagonistic activity against Rhinocladiella sp. (culture collection of the Institute of Plant Sciences, University of Graz) in dual-culture experiments, (v) chitinase activity on chitin agar and in chitin-RBV assay, (vi) $\beta$-glucanase activity with chromogenic AZCL-Barley $\beta$-glucan.

\section{Two Clamp VOCs Assays (TCVAs)}

Depending on the experiment type, 6-, 12-, and 24-well plates (Greiner Bio-One, Frickenhausen, Germany) were used together with a perforated $(0.5 \mathrm{~cm} \varnothing) 1 \mathrm{~mm}$ silicone foil (detailed specifications are presented in Table S1) for tightening connected wells and usual clamps for fixation. Sterile plates were acquired and the silicone foils used were washed and autoclaved at $121^{\circ} \mathrm{C}$ (holding time of $20 \mathrm{~min}$ ). 6-, 12-, and 24-well plates were filled with respectively $5,3.5$, and $1.5 \mathrm{~mL}$ sterile media per well. The preparation steps and the final setup are pictured sequentially in Figure S1.

\section{TCVA with $B$. cinerea and Lichen-Associated Bacteria}

The bacterial isolates were streaked onto Nutrient Agar (NA; Sifin, Berlin, Germany) in 6-well plates and pre-incubated for
$24 \mathrm{~h}$ at $30^{\circ} \mathrm{C}$. Next, $5 \mathrm{~mm}$ diameter plugs were cut from a donor plate evenly covered with $B$. cinerea. These plugs were placed in the center of each well in the 6-well plates containing Synthetic Nutrient-Poor Agar (SNA). After the inoculated plates were checked for sufficient growth, silicone foils were placed between plate pairs containing lichen isolates and B. cinerea, respectively. The plates were then clamped together; the lichen-associated bacteria plate was placed upside-down over the $B$. cinerea plates on the bottom. The plates were incubated in the dark at $21^{\circ} \mathrm{C}$ for 4 days and subsequently visually inspected for mycelium growth and compared to untreated controls (Figure 2A). Two types of controls were implemented; one containing NA wells without any bacteria and one inoculated with $E$. coli K12 instead of lichen-associated isolates.

\section{TCVA with E. coli and Lichen-Associated Bacteria}

The bacterial isolates were streaked onto NA in 12-well plates and pre-incubated for $24 \mathrm{~h}$ at $30^{\circ} \mathrm{C}$. Following the incubation time, a fluid Nutrient Broth (NB; Sifin, Berlin, Germany) culture of E. coli $\mathrm{K} 12$ was grown to an $\mathrm{OD}_{600}=0.4-0.6$. $6 \mathrm{~mL}$ aliquots were then sequentially transferred to $200 \mathrm{~mL}$ NA (20\%) supplemented with $0.2 \mathrm{mg} / \mathrm{mL}$ 2-(4-iodophenyl)-3-(4-nitrophenyl)5-phenyltetrazolium chloride (INT; Sigma-Aldrich, St. Louis, MO, USA) and immediately pipetted into sterile 12 -well plates. 


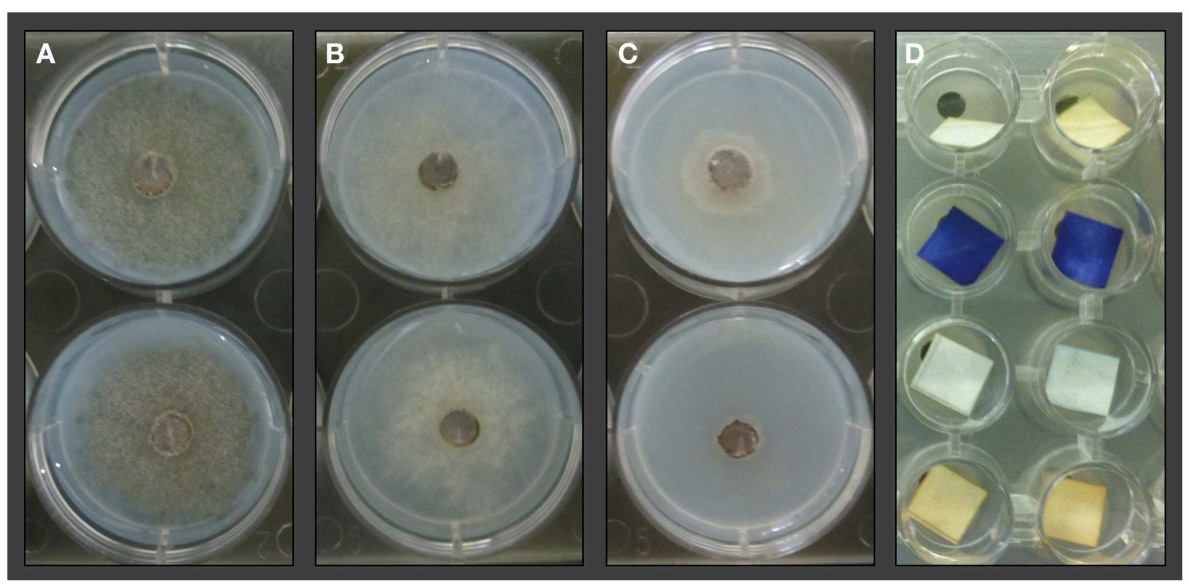

FIGURE 2 | TCVA with lichen-associated bacterial isolates and Botrytis cinerea. Mycelium growth and sporulation was compared to untreated controls (A) after 4 days of co-incubation. Inhibition of sporulation was recorded for wells where discoloring of the mycelium was not observable (B). Inhibition of mycelial growth was recorded for wells with 50\% or less mycelium proliferation (C) compared to negative controls. TCVA with HCN indicator (D) based on copper(II) ethyloacetoacetate and 4,4'-methylenebis(N,N-dimethylaniline). The second row shows positive reactions where bacterial isolates from counterpart wells secreted HCN into the headspace which led to the color change of indicator strips.
INT can be utilized to detect dehydrogenase activity due to visible color changes. Hence, approximate differences in bacterial abundance can be correlated to the grade of visible discoloring of INTsupplemented growth medium. After solidification of the E. coli K12 containing plates, silicone foils were placed between plate pairs containing lichen isolates and $E$. coli $\mathrm{K} 12$, respectively. The plates were then clamped together; the lichen-associated bacteria plate was placed upside-down over the E. coli K12 plates on the bottom. After $24 \mathrm{~h}$ incubation at $21^{\circ} \mathrm{C}$, the plates were checked for differences in indicator color change and compared to positive and negative controls. Positive controls were obtained using different commercial disinfectants to determine sufficient $\mathrm{OD}_{600}$ values (0.4-0.6) for E. coli $\mathrm{K} 12$ and an adequate concentration of INT (Figure S2). Two types of negative controls were implemented: one containing NA wells without any bacteria, and one inoculated with $E$. coli $\mathrm{K} 12$ instead of lichen-associated isolates.

\section{qPCR Validation of TCVA Results}

This experiment is an adaption of the aforementioned TCVA with $E$. coli $\mathrm{K} 12$, the only modification being that semi-solid $0.3 \%$ NA was used instead of solid $1.5 \%$ NA in the initial steps of the experiment. After the incubation time, $500 \mu \mathrm{L}$ of the semi-solid medium with $E$. coli $\mathrm{K} 12$ and INT was transferred into $2 \mathrm{~mL}$ reaction tubes with $1 \mathrm{~mL} 0.85 \% \mathrm{NaCl}$ and subsequently dissolved via vortex. Each tube was supplemented with $10 \mu \mathrm{L}$ (1:100 solution) propidium monoazide (PMA; GenIUL, Barcelona, Spain) and incubated on ice in the dark while shaking at $100 \mathrm{rpm}$ for $50 \mathrm{~min}$. The tube lids were then opened after incubation and placed under a LED light source for activation of PMA with an emission maximum of $520 \mathrm{~nm}$ for $10 \mathrm{~min}$. PMA forms covalent bonds with available DNA but cannot pass through undisrupted cell membranes. This step was performed to exclusively detect gene fragments from living E. coli K12 in the qPCR-based quantification. The suspension was then transferred to glass bead containing tubes and mechanically disrupted for $2 \times 45 \mathrm{~s}$ at $6 \mathrm{~m} / \mathrm{s}$ with a FastPrep ${ }^{\circledR}-24$ Instrument (MP Biomedicals Europe, Illkirch, France) and centrifuged at $3000 \times \mathrm{g}$ for $2 \mathrm{~min}$ to sediment beads and residual Agar. DNA was subsequently extracted from $500 \mu \mathrm{L}$ of supernatant using the GeneJET Genomic DNA Purification Kit (Thermo Scientific, Waltham, MA, USA). Quantification of $16 \mathrm{~S}$ rDNA fragments from the DNA extract was conducted with primer pair Unibac-II-515f/Unibac-II-927r as described by Lieber et al. (2003), and standards containing the Unibac-II fragments were prepared according to Köberl et al. (2011). For standard preparation, the gene fragments from Bacillus subtilis subsp. subtilis Sd3-12 were cloned into the pGEM $^{\circledR}$-T Easy Vector (Promega, Madison, WI, USA) and later re-amplified with vector specific primers. Total DNA extract treated with amplificationgrade DNase I (Sigma-Aldrich, St. Louis, MO, USA) was used to determine the inhibitory effects of co-extracted substances. Based on these results, the extracted DNA was then diluted 1:10 and the target regions were amplified using KAPA SYBR FAST qPCR Kit (Kapa Biosystems, Woburn, MA, USA). Two independent runs with three replicates for each sample were performed on the Rotor Gene 6000 (Corbett Research, Mortlake, Australia) according to Bragina et al. (2013). The specificity of the amplicons and qPCR products was confirmed using melting-curve analysis and gel-electrophoresis, respectively.

\section{TCVA with a Hydrogen Cyanide (HCN) Indicator and Lichen-Associated Bacteria}

The bacterial isolates were streaked onto NA in 24-well plates and pre-incubated for $24 \mathrm{~h}$ at $30^{\circ} \mathrm{C}$. Indicator strips were prepared using blotting paper submerged in $10 \mathrm{~mL}$ chloroform (Carl Roth, Karlsruhe, Germany) solution with $50 \mathrm{mg}$ copper(II) ethylacetoacetate (Sigma-Aldrich, St. Louis, MO, USA) and $50 \mathrm{mg} 4,4-$ methylenebis(N,N-dimethylaniline) (Sigma-Aldrich, St. Louis, MO, USA) and left to air dry. After the pre-incubation time, 
$1 \times 1 \mathrm{~cm} \mathrm{HCN}$ indicator strips were placed in each well of a 24-well plate. Silicone foils were placed between the upside-down lichen-associated bacteria plates and those containing the $\mathrm{HCN}$ indicators. The plate pairs were then clamped together and incubated for $48 \mathrm{~h}$ at $30^{\circ} \mathrm{C}$. Lastly, the indicator plates were checked for an intense blue color change in the corresponding upper wells. Negative controls were conducted with non-inoculated NA wells.

\section{Identification of Active Isolates by 165 rDNA Sequencing}

Isolated DNA from pure cultures was amplified with primer pair 27F/1492r according to Lane (1991). The PCR product was purified with Wizard ${ }^{\circledR}$ SV Gel and PCR Clean-Up System (Promega, Madison; WI, USA) followed by Sanger sequencing (LGC Genomics, Berlin, Germany). The sequences were aligned with BLASTn (http://blast.ncbi.nlm.nih.gov/Blast.cgi) and 16S ribosomal RNA sequences database. Identification of the closest match was applied for the retrieved results.

\section{Headspace SPME and GC/MS Analysis of Bacterial VOCs}

The utilized GC/MS SPME headspace method was adapted with minor changes from Verginer et al. (2010). For sample preparation from bacterial isolates, single colonies were transferred with an inoculating loop on $10 \mathrm{~mL} \mathrm{NA}$ slope agar (1.5\%) in $20 \mathrm{~mL}$ headspace vials $(75.5 \times 22.5 \mathrm{~mm}$; Chromtech, Idstein, Germany). The isolates were streaked out in 3 parallel lanes to ensure similar bacterial lawn density after incubation. Following $48 \mathrm{~h}$ of incubation at $30^{\circ} \mathrm{C}$ the vials were sealed with adequate crimp seals and incubated for additional $2 \mathrm{~h}$. Solid phase micro extraction (SPME) was performed with an automated sampler and 50/30 $\mu \mathrm{m}$ Divinylbenzen/CarboxenTM/ Polydimethylsiloxane (PDMS) $2 \mathrm{~cm}$ Stableflex/SS fiber (Supelco, Bellefonte, PA, USA). Volatile compounds were enriched for $30 \mathrm{~min}$ at $30^{\circ} \mathrm{C}$. Compound separation and detection was performed on a system combining a GC 7890A with a quadrupol MS 5975C (Agilent Technologies, Waldbronn, Germany). Samples were run through a (5\%-phenyl)methylpolysiloxane column, $60 \mathrm{~m} \times 0.25 \mathrm{~mm}$ i.d., $0.25 \mu \mathrm{m}$ film thickness (DB-5MS; Agilent Technologies, Waldbronn, Germany), followed by electron ionization (EI; $70 \mathrm{eV}$ ) and detection (mass range 25-350). The inlet temperature was adjusted to $270^{\circ} \mathrm{C}$. For the temperature gradient the GC column was kept at $40^{\circ} \mathrm{C}$ for $2 \mathrm{~min}$, raised to $110^{\circ} \mathrm{C}$ at a rate of $5^{\circ} \mathrm{C} / \mathrm{min}$, then to $280^{\circ} \mathrm{C}$ at $10^{\circ} \mathrm{C} / \mathrm{min}$ and finally maintained at $280^{\circ} \mathrm{C}$ for $3 \mathrm{~min}$. The helium flow rate was set to $1.2 \mathrm{~mL} / \mathrm{min}$. Serial analysis was done with up to 12 samples per run. Obtained spectra were compared with NIST Mass Spectral Database 08 entries. Specific compounds were identified based on their retention indices and comparison to reference substances (Sigma-Aldrich, St. Louis, MO, USA). Origin 8.5 (OriginLab, Northampton, MA, USA) was applied for visualization of total ion chromatograms (TICs). Background-subtracted mass spectra were used for the depiction of unidentified substances.

\section{Statistical Analysis}

The statistical analysis was conducted with ANOVA within RStudio (version 0.97.551) and one-sided $t$-test $(P<0.001)$. Gene copy numbers of the UniBac-II fragment from TCVA-exposed samples $(n=36)$ were compared to untreated controls $(n=$ 12 ). The gene copy numbers were obtained from two biological samples and three qPCR repeats respectively.

\section{Results}

\section{Testing Volatile Activity Against E. coli and Botrytis Cinerea}

The here presented Two Clamp VOCs Assay (TCVA) made it possible to detect bioactive VOC producers within 100 lichenassociated bacterial isolates. Sporulation reduction (Figure 2B) was demonstrated for five isolates; four isolates reduced sporulation of $B$. cinerea in three out of four replicate experiments, while one isolate reduced sporulation in all four trials. $B$. cinerea growth was repeatedly reduced after exposure to 21 different lichenassociated bacterial isolates in the TCVA, and mycelium proliferation was visibly affected (Figure 2C) for these isolates when compared to negative controls. Moreover, 16 isolates reduced proliferation in three out of four replicate experiments, while five isolates reduced proliferation in all four trials. Only one of the identified growth-reducing isolates was later shown to release HCN into the headspace. TCVAs with E. coli allowed identification of 10 lichen-associated isolates that are associated with the exertion of antagonistic activity through headspace. Low INTbased growth media discoloring indicating a reduced number of metabolically active bacteria was observed in all three replicate experiments. Comparison to the corresponding HCN TCVAs showed that two of the growth-reducing isolates did not release HCN into headspace. Only one isolate inhibited the growth of both target organisms and was later identified as Pseudomonas umsongensis 313P5BS. From all identified antagonists we have selected the 15 most active isolates against one or both target organisms and one non-inhibiting isolate for Sanger sequencing (Table 1).

\section{Screening for HCN Producers}

All lichen isolates were tested for HCN production in a modified TCVA by imposing indicator strips to the headspace. Nine bacterial isolates induced dark blue discoloring of the indicator strips in all three replicate experiments. Eight of the identified HCNproducing isolates also reduced growth of E. coli in previous experiments. These isolates were later assigned to Pseudomonas spp., while the non-antagonistic HCN producer had the highest sequence similarity to a Bacillus pumilus isolate.

\section{Validation of TCVA Results by Quantitative PCR}

DNA extracts from wells containing $E$. coli that had shown low discoloring of INT after exposition to lichen-associated bacteria were used to determine the gene copy number of the Unibac-II fragment. DNA from dead or disrupted cells was blocked by PMA which enabled a correlation between gene copy number and living cells. A significantly lower gene copy number compared to controls was shown for all samples exposed to the headspace of highly active antagonists that were pre-screened based on INT discoloring. An approximately 4-fold decrease of the gene copy 


\begin{tabular}{|c|c|c|c|c|c|}
\hline Strain ID & $\begin{array}{l}\text { Closest BLASTn } \\
\text { match }\end{array}$ & $\begin{array}{l}\text { GenBank } \\
\text { accession } \\
\#\end{array}$ & $\begin{array}{l}\text { Inhibition } \\
\text { of } E \text {. coli }\end{array}$ & $\begin{array}{l}\text { Inhibition } \\
\text { of } B \text {. } \\
\text { cinerea }\end{array}$ & $\begin{array}{c}\text { HCN } \\
\text { producer }\end{array}$ \\
\hline 43P2BR & Bacillus pumilus & KP739785 & & $\checkmark$ & \\
\hline 236P5S & $\begin{array}{l}\text { Pseudomonas } \\
\text { umsongensis }\end{array}$ & KP739786 & $\checkmark$ & & $\checkmark$ \\
\hline 268P3S & $\begin{array}{l}\text { Pseudomonas } \\
\text { umsongensis }\end{array}$ & KP739787 & $\checkmark$ & & $\checkmark$ \\
\hline 269P3R & $\begin{array}{l}\text { Burkholderia } \\
\text { sordidicola }\end{array}$ & KP739788 & $\checkmark$ & & \\
\hline 271P3S & $\begin{array}{l}\text { Pseudomonas } \\
\text { umsongensis }\end{array}$ & KP739789 & $\checkmark$ & & $\checkmark$ \\
\hline 279P5I & $\begin{array}{l}\text { Pseudomonas } \\
\text { umsongensis }\end{array}$ & KP739790 & $\checkmark$ & & $\checkmark$ \\
\hline 288P4R & $\begin{array}{l}\text { Burkholderia } \\
\text { sordidicola }\end{array}$ & KP739791 & $\checkmark$ & & \\
\hline 293P5BI & $\begin{array}{l}\text { Pseudomonas } \\
\text { umsongensis }\end{array}$ & KP739792 & $\checkmark$ & & $\checkmark$ \\
\hline 300P5BR & $\begin{array}{l}\text { Chryseobacterium } \\
\text { piscium }\end{array}$ & KP739793 & & $\checkmark$ & \\
\hline 301P5BS & $\begin{array}{l}\text { Pseudomonas } \\
\text { umsongensis }\end{array}$ & KP739794 & $\checkmark$ & & $\checkmark$ \\
\hline 313P5BS & $\begin{array}{l}\text { Pseudomonas } \\
\text { umsongensis }\end{array}$ & KP739795 & $\checkmark$ & $\checkmark$ & $\checkmark$ \\
\hline 409P5 & Pseudomonas lini & KP739796 & $\checkmark$ & & $\checkmark$ \\
\hline 418P4B & $\begin{array}{l}\text { Stenotrophomonas } \\
\text { rhizophila }\end{array}$ & KP739797 & & $\checkmark$ & \\
\hline 439P1B & $\begin{array}{l}\text { Stenotrophomonas } \\
\text { rhizophila }\end{array}$ & KP739798 & & $\checkmark$ & \\
\hline 460P5B & $\begin{array}{l}\text { Stenotrophomonas } \\
\text { rhizophila }\end{array}$ & KP739799 & & $\checkmark$ & \\
\hline 471P3B & Bacillus pumilus & KP739800 & & & $\checkmark$ \\
\hline
\end{tabular}

Listed species represent the closest match of BLASTn searches within the 165 ribosomal RNA sequences database (NCBI). The $16 S$ gene fragment sequences were deposited at GenBank (http://www.ncbi.nlm.nih.gov/genbank).

number was observed with the least inhibiting antagonist Pseudomonas sp. 279P5I, while the most effective antagonist Pseudomonas sp. 236P5S decreased the gene copy number of E. coli approx. 15-fold (Figure 3).

\section{Taxonomic Assignment of Active Lichen-Associated Isolates}

Sanger sequencing revealed multiple occurrence of some dominant genera. Furthermore, sequencing of $16 \mathrm{~S}$ rRNA gene fragments from the 15 most active isolates and a non-antagonistic $\mathrm{HCN}$ producer revealed the majority belonging to the genus Pseudomonas (8 isolates), followed by Stenotrophomonas (3 isolates) and three other genera with lower occurrence: Bacillus, Burkholderia, and Chryseobacterium. Utilization of the TCVA demonstrated that E. coli inhibition was mostly observed after exposure to the headspace of Pseudomonas sp., while $B$. cinerea growth reduction was mostly observed after exposition to the headspace of Stenotrophomonas rhizophilia. Moreover the sequencing approach revealed that different Pseudomonas sp. inhibited E. coli growth accompanied by $\mathrm{HCN}$ release into headspace. Identified isolates are presented together with corresponding TCVA results in Table $\mathbf{1}$.

\section{GC/MS-Based Headspace Analysis with Selected Isolates}

Three representative isolates which were shown to inhibit growth of headspace-exposed target microorganisms and which were taxonomically assigned to reoccurring genera were used for subsequent GC/MS headspace SPME profiling. Isolate-specific VOCs were identified by overlays of total ion chromatograms (TIC; Figure 4). A total of 21 compounds (Table S2) were found to be unique and only present in TICs of a specific isolate. Bacillus pumilus 43P2BR emitted nine distinctive volatile compounds (compound IDs: 2, 5, 8, 10, 13, 14, 15, 18, and 21), followed by Pseudomonas umsogensis 313P5BS with eight distinctive compounds (compound IDs: 1, 6, 7, 9, 16, 17, 19, and 20). S. rhizophila 418P4B was shown to emit only four distinctive compounds (compound IDs: 3, 4, 11, and 12). Compound identification indicated that $B$. pumilus 43P2BR emitted 1-butanol, 3-methyl-2-pentanone and seven unidentified substances (Figures S3-18). 2-butanol, 2-methyl-1-propanol and two unidentified substances were found within spectra of $S$. rhizophila 418P4B. Conversely, P. umsogensis 313P5BS emitted methyl thiocyanate as well as seven unidentified substances.

\section{Discussion}

The results of the screening for bacteria-derived bioactive VOCs demonstrated the applicability of a novel testing system, which is not restricted to bacteria associated with lichens, but can be widely applied with microorganisms sampled in other habitats. With the presented setup several 100 isolates can be tested simultaneously for VOCs-driven effects on target microorganisms and occurrence of specific metabolites. This facilitates screening programs for strain-specific biological effects. Thus, the method is also not limited to observations of growth inhibition such as demonstrated in the present study, but could also be used to identify growth promoting effects. The method, however, reveals the effect of the total "volatilome" of a bacterial strain and does not dissect the effect of individual substances. The composition of the mixture of volatile substances must still be assessed by chemical analysis, after which individual compounds might be tested separately.

We have selected 100 isolates for evaluation purposes that met predefined criteria such as antagonism in classic dual-culture experiments. Thus, we expected to identify a sufficient number of isolates which emit bioactive VOCs to validate the experimental design and the presented workflow. Utilization of different TCVA variations allowed the identification of 30 growth inhibiting bacterial isolates with a novel and reliable technique. Subsequent analysis of the headspace from taxonomically dissimilar bacterial isolates by employing headspace SPME GC/MS demonstrated the presence of isolate-specific TIC profiles and unique compounds in each sample. We have identified five out of 21 unique compounds, emitted by three distinct bacterial strains, to exemplify the presented workflow. While some compounds most likely originate from bacterial degradation of growth media 


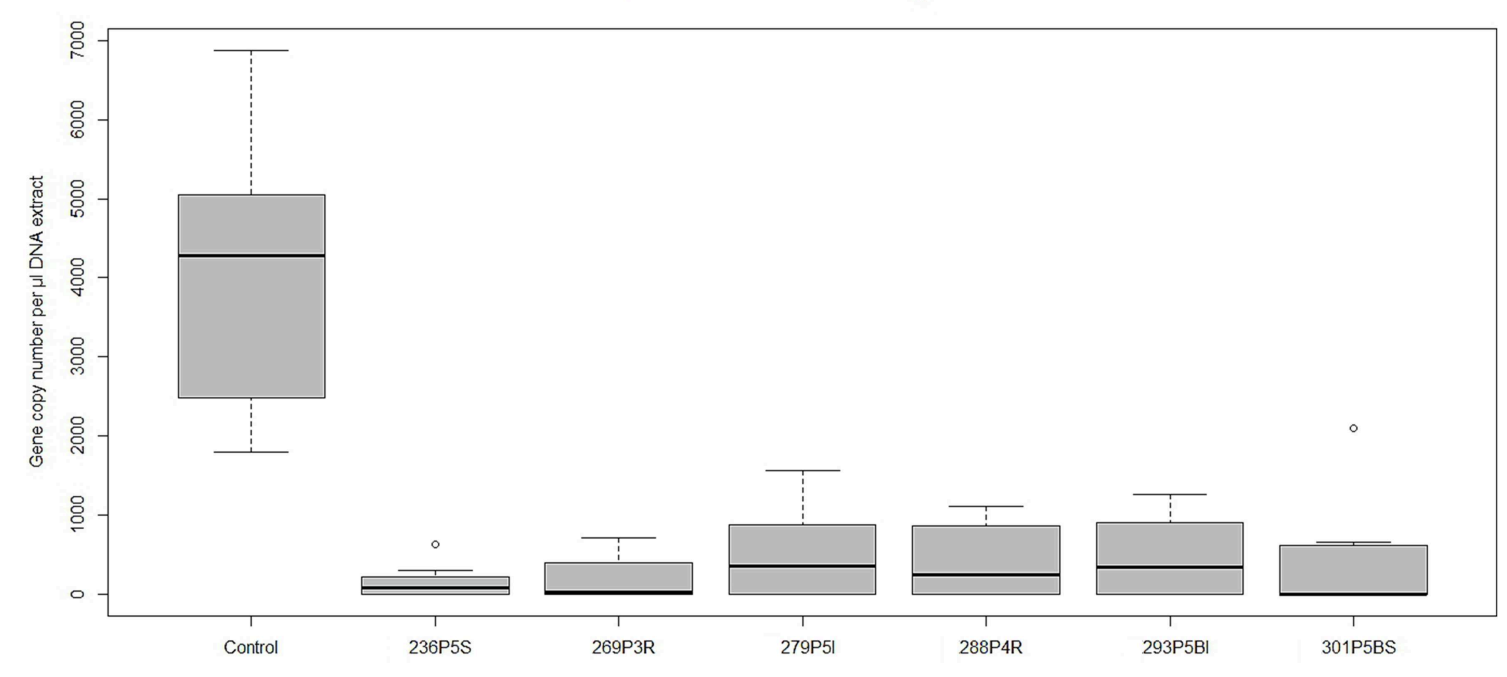

FIGURE 3 | A qPCR approach was used to determine gene copy numbers of $E$. coli K12 after exposition to strong VOCs antagonists.

TCVA-exposed samples were treated with PMA and gene copy numbers of viable cells were quantified with Unibac-II primers. Values for the treated samples were obtained from respectively six qPCR runs and additional 12 qPCR runs for untreated controls. Statistical analysis with ANOVA and one-sided $t$-test confirmed a highly significant decrease of gene copy numbers of the treated samples compared to the control group $(P<0.001)$. (waste products of bacterial metabolism) and therefore do not target pathogens specifically, other compounds might either be involved in molecular signaling or inhibition of competing organisms. These differences and their significance in natural systems merit further exploration. It might be hypothesized that bacterial bioconversion of the natural substrate may result in volatile compounds with signaling effect. Specifically, the odor of lichens, which may attract reindeer or is part of perfumes, could be influenced not only by the genuine compounds produced by the fungal or algal symbiont, but possibly also by VOCs produced by the bacteria themselves or by compounds released from the fungal matrix due to the metabolic activity of associated bacteria.

The presented workflow includes a pre-incubation of the tested isolates to minimize their inhibition by volatiles emitted by the target organisms. Due to intended growth advantage of the tested organisms, emitted volatiles from the target organisms might not play an important role during the co-incubation. Still, such effects cannot be completely avoided with the presented setup. An inverted approach where the "target" is preincubated and subsequently tested against the respective isolate collection could be implemented to obtain a more holistic view on occurring interactions.

Interestingly, $P$. umsongensis, a bacterial species isolated from soil as well as from fungal hyphae and described as "fungiphilic" (Warmink et al., 2009), was the only representative of Pseudomonas isolates that consistently inhibited $B$. cinerea growth. This may have resulted from better and faster growth on solid medium compared to the other utilized strains and therefore a higher accumulation of cyanide in the headspace. Various Pseudomonas species are known to be cyanogenic bacteria and therefore enhanced toxicity toward various prokaryotes and eukaryotes can be expected even if they are not in close contact. While the employed headspace SPME GC/MS method was not suitable for detection of hydrogen cyanide, we were able to detect methyl thiocyanate above cultures of P. umsongensis 313P5BS. Conversion of cyanide to thiocyanate is accomplished by bacterial rhodanese and these co-occurring molecules can be extracted simultaneously from headspace above living cultures (Broderick et al., 2008). Weise et al. (2013) have highlighted the importance of bacterial ammonia production and demonstrated accompanied growth inhibition of Arabidopsis thaliana. Specific indicator stripes in the TCVA would allow to test for ammonia in the headspace, which would also imply an unspecific inhibition of target organisms.

Some bacteria are well known for pronounced antifungal effects against phytopathogenic fungi. This effect is typical for several strains belonging to Stenotrophomonas (Wolf et al., 2002), which was also observed with headspace experiments (Ryan et al., 2009). Bacillus species were shown in prior studies not only to produce antifungal VOCs (Fiddaman and Rossall, 1993), but also volatiles that promoted growth in A. thaliana (Ryu et al., 2003). Our study demonstrates such antagonistic effects with a robust well plate-based approach and provides various options for modifications to study further effects e.g., growth promotion of bacteria on plants in an adaptable testing system. Moreover, this approach could also be applied to study the prevalence of similar bioactive effects across entire bacterial genera and to correlate volatile effects with the occurrence of strains in particular ecological niches.

As we are convinced that bacterial volatiles might play an important role to modify the composition of host-associated communities, future research needs to focus on the, possibly context-dependent, effects of such small molecules. We anticipate 


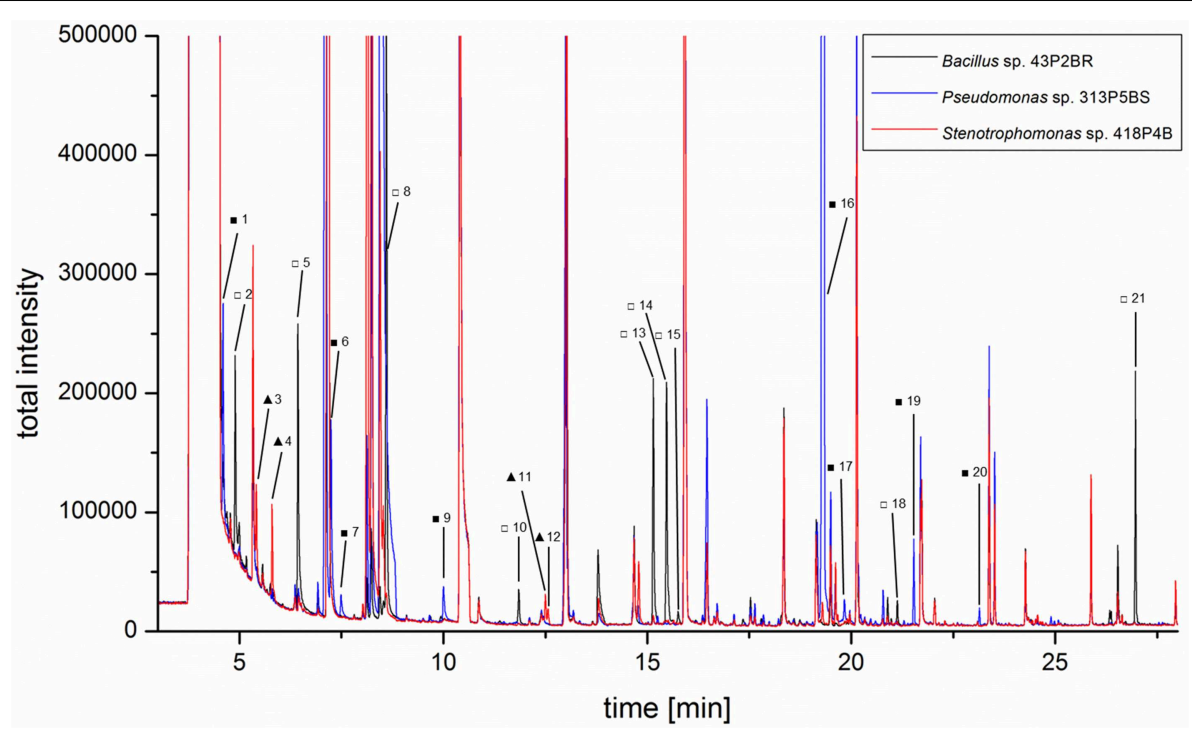

FIGURE 4 | Three lichen-associated bacterial isolates were subjected to headspace SPME GC/MS analysis to identify isolate-specific VOC profiles. An overlay of the respective TIC chromatograms illustrates the presence of specific metabolites in the headspace of Bacillus pumilus43P2BR (empty squares), Pseudomonas umsongensis 313P5BS (filled squares), and Stenotrophomonas rhizophila 418P4B (filled triangles). Identified Bacillus-specific compounds were: 1-butanol (5口) and 3-methyl-2-pentanone (8ם). Methyl thiocyanate (7ם) was identified as Pseudomonas-specific compound. Stenotrophomonas-specific compounds

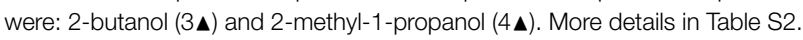

that this newly developed testing approach will be a major step forward to facilitate such studies.

\section{Acknowledgments}

This work was supported by a grant of the Austrian Science Fund (FWF) to GB and MG (FWF Project I882). We want to thank Angelika Schäfer (Graz), Nicole Pabi (Graz), and Georg Raber (Graz) for their generous support and the provision of required instruments for headspace analytics. We are grateful to Lucia Muggia (Graz) for providing the culture of Rhinocladiella

\section{References}

Berg, G., Zachow, C., Müller, H., Philipps, J., and Tilcher, R. (2013). Nextgeneration bio-products sowing the seeds of success for sustainable agriculture. Agronomy 3, 648-656. doi: 10.3390/agronomy3040648

Blaser, M., Bork, P., Fraser, C., Knight, R., and Wang, J. (2013). The microbiome explored: recent insights and future challenges. Nat. Rev. Microbiol. 11, 213-217. doi: 10.1038/nrmicro2973

Blom, D., Fabbri, C., Connor, E. C., Schiestl, F. P., Klauser, D. R., Boller, T., et al. (2011). Production of plant growth modulating volatiles is widespread among rhizosphere bacteria and strongly depends on culture conditions. Environ. Microbiol. 13, 3047-3058. doi: 10.1111/j.1462-2920.2011. 02582.x

Bragina, A., Berg, C., Müller, H., Moser, D., and Berg, G. (2013). Insights into functional bacterial diversity and its effects on Alpine bog ecosystem functioning. Sci. Rep. 3:1955. doi: 10.1038/srep01955

Broderick, K. E., Chan, A., Balasubramanian, M., Feala, J., Reed, S. L., Panda, M., et al. (2008). Cyanide produced by human isolates of Pseudomonas aeruginosa contributes to lethality in Drosophila melanogaster. J. Infect. Dis. 197, 457-464. doi: $10.1086 / 525282$ sp. We appreciate the provision of pictures used in Figure 2 by Rocel Amor Ortega (Graz) and the valuable support of Alexander Mahnert (Graz) with RStudio. We also want to thank Timothy Mark (Graz) for proof-reading the manuscript and informative discussions.

\section{Supplementary Material}

The Supplementary Material for this article can be found online at: http://journal.frontiersin.org/article/10.3389/fmicb. 2015.00398/abstract

Conery, A. L., Larkins-Ford, J., Ausubel, F. M., and Kirienko, N. V. (2014). High-throughput screening for novel anti-infectives using a $C$. elegans pathogenesis model. Curr. Protoc. Chem. Biol. 6, 25-37. doi: 10.1002/9780470559277.ch130160

Cook, R. J. (1990). “Towards biological control with introduced antagonists," in Biological Control of Soil-Borne Plant Pathogens, ed D. Hornby (Wallingford: CAB International), 6-10.

Effmert, U., Kalderás, J., Warnke, R., and Piechulla, B. (2012). Volatile mediated interactions between bacteria and fungi in the soil. J. Chem. Ecol. 38, 665-703. doi: 10.1007/s10886-012-0135-5

Farag, M. A., Zhang, H., and Ryu, C. M. (2013). Dynamic chemical communication between plants and bacteria through airborne signals: induced resistance by bacterial volatiles. J. Chem. Ecol. 39, 1007-1018. doi: 10.1007/s10886-0130317-9

Fiddaman, P. J., and Rossall, S. (1993). The production of antifungal volatiles by Bacillus subtilis. J. Appl. Bacteriol. 74, 119-126. doi: 10.1111/j.13652672.1993.tb03004.x

Garbeva, P., Hordijk, C., Gerards, S., and de Boer, W. (2014). Volatile-mediated interactions between phylogenetically different soil bacteria. Front. Microbiol. 5:289. doi: 10.3389/fmicb.2014.00289 
Grube, M., Cardinale, M., de Castro, J. V. Jr., Müller, H., and Berg, G. (2009). Species-specific structural and functional diversity of bacterial communities in lichen symbioses. ISME J. 3, 1105-1115. doi: 10.1038/ismej.2009.63

Grube, M., Cernava, T., Soh, J., Fuchs, S., Aschenbrenner, I., Lassek, C., et al. (2015). Exploring functional contexts of symbiotic sustain within lichen-associated bacteria by comparative omics. ISME J. 9, 412-424. doi: 10.1038/ismej.2014.138

Joulain, D., and Tabacchi, R. (2009). Lichen extracts as raw materials in perfumery. Flavour Frag. J. 24, 105-116.

Kai, M., Effmert, U., Berg, G. and Piechulla, B. (2007). Volatiles of bacterial antagonists inhibit mycelial growth of the plant pathogen Rhizoctonia solani. Arch. Microbiol. 187, 351-60. doi: 10.1002/ffj.1923

Köberl, M., Müller, H., Ramadan, E. M., and Berg, G. (2011). Desert farming benefits from microbial potential in arid soils and promotes diversity and plant health. PLoS ONE 6:e24452. doi: 10.1371/journal.pone.0024452

Küster, E., and Williams, S. T. (1964). Selection of media for isolation of Streptomycetes. Nature 202, 928-929.

Lane, D. J. (1991). "16S/23S rRNA sequencing," in Nucleic Acid Techniques in Bacterial Systematics, eds E. Stackebrandt and M. Goodfellow(Chichester: John Wiley and Sons), 115-147.

Lieber, A., Kiesel, B., and Babel, W. (2003). "Microbial diversity of soil by SSCP fingerprinting technique using TGGE Maxi System," in Ökophysiologie des Wurzelraumes, eds W. Merbach, B. W. Hütschand and J. Augustin (Stuttgart: Teubner Verlag), 61-65.

Philippot, L., Raaijmakers, J. M., Lemanceau, P., and van der Putten, W. H. (2013). Going back to the roots: the microbial ecology of the rhizosphere. Nat. Rev. Microbiol. 11, 789-799. doi: 10.1038/nrmicro3109

Ryan, R. P., Monchy, S., Cardinale, M., Taghavi, S., Crossman, L., Avison, M. B., et al. (2009). The versatility and adaptation of bacteria from the genus Stenotrophomonas. Nat. Rev. Microbiol. 7, 514-525. doi: 10.1038/nrmicro2163

Ryu, C. M., Farag, M. A., Hu, C. H., Reddy, M. S., Wei, H. X., Paré, P. W., et al. (2003). Bacterial volatiles promote growth in Arabidopsis. Proc. Natl. Acad. Sci. U.S.A. 100, 4927-4932. doi: 10.1073/pnas.0730845100

Schalchli, H., Tortella, G. R., Rubilar, O., Parra, L., Hormazabal, E., and Quiroz, A. (2014). Fungal volatiles: an environmentally friendly tool to control pathogenic microorganisms in plants. Crit. Rev. Biotechnol. 8, 1-9. doi: 10.3109/07388551.2014.946466

Schrader, P. S., Burrows, E. H., and Ely, R. L. (2008). High-throughput screening assay for biological hydrogen production. Anal. Chem. 80, 4014-4019. doi: $10.1021 / \mathrm{ac} 702633 \mathrm{q}$
Seyedsayamdost, M. R. (2014). High-throughput platform for the discovery of elicitors of silent bacterial gene clusters. Proc. Natl. Acad. Sci. U.S.A. 111, 7266-7271. doi: 10.1073/pnas.1400019111

Shirling, E. T., and Gottlieb, D. (1966). Method for characterization of Streptomyces species. Int. J. Syst. Bacteriol. 16, 313-340.

Strobel, G. (2006). Harnessing endophytes for industrial microbiology. Curr. Opin. Microbiol. 9, 240-244. doi: 10.1016/j.mib.2006.04.001

Verginer, M., Leitner, E., and Berg, G. (2010). Production of volatile metabolites by grape-associated microorganisms. J. Agric Food Chem. 58, 8344-8350. doi: 10.1021/jf100393w

Vespermann, A., Kai, M., and Piechulla, B. (2007). Rhizobacterial volatiles affect the growth of fungi and Arabidopsis thaliana. Appl. Environ. Microbiol. 73, 5639-5641. doi: 10.1128/AEM.01078-07

Warmink, J. A., Nazir, R., and van Elsas, J. D. (2009). Universal and speciesspecific bacterial 'fungiphiles' in the mycospheres of different basidiomycetous fungi. Environ. Microbiol. 11, 300-312. doi: 10.1111/j.1462-2920.2008. 01767.x

Weise, T., Kai, M., and Piechulla, B. (2013). Bacterial ammonia causes significant plant growth inhibition. PLoS ONE 8:e63538. doi: 10.1371/journal.pone.0063538

Weller, D. M., Raaijmakers, J. M., Gardener, B. B. M., and Thomashow, L. S. (2002). Microbial populations responsible for specific soil suppressiveness to plant pathogens. Annu. Rev. Phytopathol. 40, 309-348.

Wolf, A., Fritze, A., Hagemann, M., and Berg, G. (2002). Stenotrophomonas rhizophila sp. nov., a novel plant-associated bacterium with antifungal properties. Int. J. Syst. Evol. Microbiol. 52, 1937-1944. doi: 10.1099/ijs.0.02135-0

Woolhouse, M., and Farrar, J. (2014). Policy: an intergovernmental panel on antimicrobial resistance. Nature 509, 555-557. doi: 10.1038/ $509555 \mathrm{a}$

Conflict of Interest Statement: The authors declare that the research was conducted in the absence of any commercial or financial relationships that could be construed as a potential conflict of interest.

Copyright (C) 2015 Cernava, Aschenbrenner, Grube, Liebminger and Berg. This is an open-access article distributed under the terms of the Creative Commons Attribution License (CC BY). The use, distribution or reproduction in other forums is permitted, provided the original author(s) or licensor are credited and that the original publication in this journal is cited, in accordance with accepted academic practice. No use, distribution or reproduction is permitted which does not comply with these terms. 